\title{
Kehidupan Sehat dan Sejahtera Melalui Olah Tanah Berbasis Keanekaragaman Hayati
}

\author{
Familia Novita Simanjuntak ${ }^{1^{*}}$ \\ ${ }^{1}$ Universitas Kristen Indonesia, Jalan Mayjen Sutoyo No. 2, Cawang, Jakarta Timur
}

\section{Kata Kunci: \\ Keanekaragaman hayati, pertanian organis, kehidupan sehat dan sejahtera, SDGs}

\section{Keywords:}

Biodiversity, organic farming, good health and well-being, SDGs

\begin{abstract}
Abstrak
Pencapaian kehidupan sehat dan sejahtera membutuhkan pendekatan yang bersifat multi-disiplin dan multi-dimensi. Salah satu dimensi tersebut adalah fasilitas lingkungan hidup yang dapat menopang kebutuhan kehidupan dan menampung semua dampak dari aktifitas kehidupan tersebut. Olah tanah berbasis keanekaragaman hayati merupakan sebuah upaya terintegrasi dalam rangka penguatan fasilitas lingkungan hidup untuk melindungi, memulihkan, dan mendukung penggunaan ekosistem daratan secara berkelanjutan. Pertumbuhan populasi manusia yang cenderung meningkat berdampak pada kualitas tanah yang semakin terdegradasi akibat eksploitasi dan alih fungsi untuk memfasilitasi kebutuhan kehidupan manusia. Artikel ini membahas melalui kajian literatur terkait praktek pertanian organis sebagai olah tanah berbasis keanekaragaman hayati untuk meningkatkan kualitas kesuburan tanah sebagai salah satu indikator fasilitas lingkungan hidup. Artikel menggunakan hasil penelitian tentang pertanian organis BSB Cisarua Bogor (2006) sebagai landasan kajian literatur. Hasil penelitian menyatakan bahwa pertanian organis BSB Cisarua meningkatkan kualitas kesuburan tanah sebagai indikator daya dukung dan daya tampung tanah melalui olah tanah berbasis keanekaragaman hayati di atas dan bawah tanah untuk menghasilkan produk pertanian yang bebas dari bahan kimia sintetis.

Abstract

To achieve good health and well-being, we need a multi-disciplinary and multi-dimensional approach. The environmental facility is the one of dimension which supports the being's life and carries the impact of its activities. Soil application based on biodiversity can be an integrated effort to strengthen the environmental facility to protect, preserve, and promote the sustainable ecosystem on land exploitation. The increasing human population affects the degradation of soil quality as the impact of the overexploitation and conversion on land utilization to fulfill the population needs. This paper uses the literature review to discuss organic farming as the soil application based on biodiversity that improves the quality of soil fertility as one indicator of the environmental facility. This paper also uses the research funding on BSB Cisarua organic farming (2006) as the basic reference of literature review. The research findings state that BSB Cisarua organic farming products are free of the synthetic chemical through soil application based on biodiversity above and below the soil that improves the quality of soil fertility as the land carrying capacity.
\end{abstract}

\footnotetext{
*Penulis koresponden: familia.simanjuntak@uki.ac.id
} 


\section{PENDAHULUAN}

Tanah sebagai komponen ekosistem berinteraksi dan dipengaruhi oleh komponen ekosistem lain, termasuk atmosfer, air, dan organisme (Gregorich \& Carter 1997, 121). Saling ketergantungan antara organisme dan lingkungan fisiknya memang tidak terlihat di tanah, namun interaksi yang kuat antara tanaman, mikroorganisme dengan konstituen tanah menentukan kondisi lingkungan dan komposisi spesies.

Tanah mempengaruhi ketersediaan dan kualitas pangan (ketahanan pangan) serta paparan manusia terhadap beragam bahan kimia dan patogen melalui ketersediaan hara tanah yang masuk dalam rantai makanan dan jejaring paparan (Brevik \& Sauer 2015, 35-46). Sehingga, kualitas tanah dapat mempengaruhi kesehatan manusia secara utuh melalui penyediaan kebutuhan fisik dan non fisik (psikologi). Corkery (2015, 273-287) mengkaji keterkaitan alam dengan kesehatan mental, yaitu tanah yang berkualitas akan menciptakan kondisi alam yang secara kondusif mengurangi rentang waktu bagi manusia untuk pulih dan pengobatan penyakit sekaligus mengurangi tekanan darah tinggi.

Lebih lanjut, Brevik \& Sauer (2015) menyatakan bahwa kajian keterkaitan kualitas tanah dengan kehidupan sehat dan sejahtera sudah terjadi sejak tahun 400 sebelum Masehi yaitu saat Hipokrates memasukkan kesehatan tanah ke dalam daftar evaluasi pengobatannya, bahkan ayat kitab suci juga ada menyebutkan bahwa kualitas tanah berkaitan dengan kualitas hidup manusia. Bahkan, Barrett, Christopher, \& Leah (2015) menyatakan bahwa kualitas tanah berdampak pada kondisi ekonomi rumah tangga terkait produktifitas manusia yang bergantung pada kualitas tanah.

Oleh karena itu, artikel ini mengkaji relevansi kualitas tanah sebagai salah satu fasilitas lingkungan hidup dalam kehidupan manusia pada kondisi padat penduduk untuk lebih sehat dan sejahtera. Artikel ini, secara khusus, membahas pemanfaatan tanah untuk produksi sayur-mayur sebagai asupan gizi yang harus dikonsumsi $5 \mathrm{x}$ dalam porsi cukup setiap hari dalam rangka peningkatan kualitas hidup sehat dan sejahtera (Dhandevi \& Jeewon 2015). Produksi sayur-mayur dari tanah yang diolah secara sehat memberi efek tambahan pada kualitas udara yang lebih baik dan penurunan risiko paparan manusia terhadap bahan kimia sintetis berbahaya (Lichtfouse 2012, 208).

Produksi sayur-mayur di sekitar rumah, selain dapat menciptakan kualitas udara mikro yang lebih baik, juga membangun ketahanan pangan skala rumah tangga (Marsden \& Sonnino 2012). Konsumsi sayur-mayur secara teratur dalam porsi tepat, menurut Lichtfouse (2012, 187), dapat mengurangi risiko kanker dan penyakit jantung yang berdampak pada pengendalian prevalensi PTM (Penyakit Tidak Menular) kanker dan jantung kronis yang secara simultan akan berdampak pada biaya kesehatan skala rumah tangga (Rahmi 2017). Penyakit tidak menular kanker dan jantung, menurut Ermalena (2017), termasuk dalam daftar indikator kesehatan SDGs. Pengendalian PTM kanker dan jantung yang dipengaruhi oleh persepsi (pengetahuan) dan pendapatan keluarga (Napirah, Rahman, \& Tony 2016) akan berdampak pada layanan BPJS Kesehatan (Syarifain, Rumayar, \& Mandagi 2017).

Lebih mendalam, tanah yang berkualitas mendapat dukungan dari keanekaragaman hayati (Taylor \& Hochuli 2014, 747-762). Tanah sehat dengan dukungan keanekaragaman hayati dapat menjalankan fungsi ekosistem yang sehat sehingga dapat menyediakan udara yang sehat, produk pangan yang bersih, dan cadangan air layak konsumsi. Frąc et al. (2018) menjabarkan bahwa keanekaragaman hayati dalam ekosistem lahan mengutamakan pada fungsi dan interaksi antar organisme sebagai penggerak aktifitas tanah sehat.

Kementerian Lingkungan Hidup dan Kehutanan (KLHK, 2018) mencatat bahwa luas lahan kritis di Indonesia mencapai 14.01 juta hektar akibat degradasi lahan. Rouf Alghifari, Dinul Dzakiah, \& Khulwatul Jannah Asrin (2019) menyatakan bahwa penyebab utama degradasi lahan adalah meningkatnya laju pembangunan dan pertumbuhan penduduk. Lebih lanjut, degradasi lahan didefinisikan sebagai penurunan produktifitas lahan yang membuat lahan tersebut menjadi kritis, tidak produktif, atau lahan tidur. Degradasi lahan dapat bersifat sementara ataupun tetap.

Pemberian pemulih keasaman tanah dan bahan organik antara lain pupuk organik dan kompos baik dalam bentuk padatan maupun cairan merupakan upaya pemulihan kesehatan lahan kritis melalui peningkatan produktifitas lahan (Tindaon, Ferisman, \& Tualar Simarmata 
2011). Keanekaragaman hayati dalam praktek pertanian dapat dilihat pada aplikasi tanaman campur dalam satu bedeng. Tanaman campur tersebut untuk mengendalikan agen pembawa penyakit (patogen) terbawa tanah dan paparan manusia terhadap bahan kimia sintetik sebagai fungisida (Lichtfouse 2010, 119).

Tanaman campur, menurut Schjønning, Elmholt, \& Christensen (2003, 140-219), membentuk keragaman yang dapat menstabilkan ekosistem tanah sebagai pertahanan terhadap stres dan gangguan akibat aktifitas yang menyebabkan berkurangnya jumlah spesies. Kualitas tanah ditentukan oleh produktifitas biota tanah yang membutuhkan asupan dari bahan organik sebagai makanannya. Aktifitas biota tersebut secara berkala akan membentuk struktur tanah yang sehat. Lebih lanjut, bahan organik dapat diperoleh dari daur ulang sampah dapur.

Lehman et al. (2015) mendefinisikan ketahanan tanah sebagai kemampuan pulih atau adaptasi tanah terhadap stres dan gangguan sehingga komponen biologis/organisme dapat menjalankan perannya dengan baik agar tanah tetap sehat. Ketahanan tanah tersebut, menurut Groffman et al. (2015), mendapat bantuan dari aktifitas cacing tanah yang meningkatkan rasio $\mathrm{C} / \mathrm{N}$ dan pori-pori tanah. Peningkatan rasio $\mathrm{C} / \mathrm{N}$ dan pori tanah berefek baik pada daur hidrologi dan gas (udara) dalam tanah sebagai penyokong habitat bagi ragam mikroba tanah.

Lal \& Stewart $(2010,139)$ menyatakan bahwa makan dan makanan adalah sebuah aksi dari budi daya pertanian, dan tanah adalah pondasi bagi praktek budidaya tersebut. Namun, budi daya pertanian meninggalkan jejak kerusakan lingkungan hidup akibat pertumbuhan populasi manusia yang cenderung meningkat, sehingga perlu strategi untuk membangun cara berpikir yang baru bahwa budi daya pertanian, selain untuk produksi pangan, juga untuk pelestarian lingkungan hidup. Strategi yang dimaksud adalah pertanian berkelanjutan melalui olah tanah berbasis keanekaragaman hayati yang didukung oleh praktek pembalikan tanah yang seperlunya, retensi tingkat (daur ulang) residu tanaman dan menggunakan tutup permukaan tanah yang memadai, serta sistem rotasi tanaman.

Artikel ini lebih lanjut mengkaji secara literatur terkait mengenai praktek pertanian organis Bina Sarana Bhakti (BSB) Cisarua, Bogor yang telah diteliti oleh Simanjuntak (2006). Temuan penelitian tersebut mendukung pencapaian tujuan kelima belas dari Tujuan Pembangunan Berkelanjutan (SDGs) yaitu praktek pertanian yang mengolah tanah berbasis keanekaragaman hayati sebagai upaya terintegrasi dalam rangka penguatan fasilitas lingkungan hidup untuk melindungi, memulihkan, dan mendukung penggunaan ekosistem daratan secara berkelanjutan.

Kajian literatur juga akan dilanjutkan dengan pembahasan keterkaitan pengetahuan praktek pertanian organis dengan pengetahuan kimia bahan makanan terkait pilihan produk konsumsi pangan untuk membangun kesadaran makan makanan sehat (Simanjuntak 2015) dan peningkatan pengetahuan kimia pada kaum ibu yang mempunyai peran utama dalam keputusan pilihan konsumsi pangan rumah tangga kelas ekonomi menengah (Simanjuntak et al. 2019).

Peran ibu dalam rumah tangga, menurut hasil penelitian Simanjuntak (2017), memberi pengaruh pada pengetahuan dan persepsi kaum remaja terhadap keragaman bahan makanan yang menggambarkan kebiasaan makan seharihari mereka. Sehingga sejalan dengan kajian Simanjuntak et al. (2019) bahwa peran serta ibu dalam praktek pertanian organis skala rumah tangga dapat mendukung peningkatan kualitas hidup sehat yang berefek pada biaya belanja keluarga agar lebih sejahtera sebagai upaya pengendalian kemiskinan skala rumah tangga.

Tujuan kajian literatur dalam artikel ini untuk membahas peran tanah dalam kehidupan manusia yang sehat dan sejahtera dalam rangka mendorong partisipasi manusia untuk menjaga ketahanan tanah/ekosistem. Partisipasi yang diharapkan muncul berdasarkan pemahaman yang komprehensif berbasis penelitian supaya memberi efek tambahan (multiplier effect) pada kesadaran konservasi lingkungan hidup dalam produksi pangan.

\section{METODE PENELITIAN}

Artikel ini adalah kajian literatur dengan basis data penelitian Simanjuntak (2006) yang menggunakan mix-method analysis atas dua jenis data yang diperoleh. Data kualitas tanah diperoleh dari metode ekspost fakto (uji lab) dan metode wawancara untuk data sosioekonomi pekerja dan persepsi (testimoni) beberapa orang pelanggan produk organik BSB Cisarua, Bogor. Indikator kualitas tanah yang 
digunakan adalah kesuburan yang mencakup kualitas fisik, kimia, dan biologi.

Pembahasan menggunakan literatur yang relevan terkait kualitas tanah, kehidupan yang sehat dan sejahtera, praktek pertanian organis keanekaragaman hayati, dan SDGs. Pemilihan literatur berdasarkan tujuan dan objektivitas penelitian Simanjuntak (2006) yaitu praktek pertanian organis skala rumah tangga dalam rangka pencapaian tujuan ketiga SDGs terkait kehidupan sehat dan sejahtera.

Meskipun aspek sejahtera juga dapat dicapai melalui komersialisasi, namun artikel ini tidak membahas mekanisme pemasaran dan sertifikasi produk organik. Dasar pertimbangan yang digunakan adalah fokus kajian pada aksi olah tanah berbasis keanekaragaman hayati untuk mendukung pencapaian kehidupan sehat dan sejahter skala rumah tangga.

\section{HASIL DAN PEMBAHASAN}

Pertanian organis Bina Sarana Bhakti (BSB) Cisarua-Bogor telah berlangsung selama 20 tahun (Simanjuntak 2006). Analisis data terkait kualitas tanah secara fisik, kimia, dan biologi antara lain terjadinya peningkatan persentase komposisi liat yang berefek pada peningkatan pori-pori makro (kualitas fisik), rasio $\mathrm{C} / \mathrm{N}$, kandungan $\mathrm{C}, \mathrm{N}$, dan $\mathrm{BO}$ meningkat namun kandungan $\mathrm{Fe}$-tersedia menurun akibat daya serap Fe tanaman yang baik, dan mikroba tanah didominasi oleh mikroflora. Kelompok mikroflora yaitu Bacillariophyta, Chlorophyta dan Euglenophyta.

Menurut analisis tersebut, kualitas tanah BSB Cisarua memiliki ketahanan tanah yang baik (Lehman et al. 2015) karena mendapat dukungan optimum dari kualitas fisik, kimia, dan biologi tanah (Groffman et al. 2015). Hal ini dapat tercapai oleh pertanian organis BSB Cisarua yang sejalan dengan pernyataan Lal \& Stewart (2010) bahwa praktek budi daya juga dapat menjalankan fungsinya sebagai pelestari lingkungan hidup (pertanian konservasi).

Pertanian organis BSB Cisarua, Bogor, menjalankan konservasi melalui mekanisme organisme hidup yaitu faktor biotik dan abiotik yang terjadi di alam budi daya (Gregorich \& Carter 1997). Masing-masing komponen saling bekerja sama menjalankan perannya untuk menghasilkan produk organik (Schjønning, Elmholt, \& Christensen 2003; Lichtfouse 2010; Tindaon, Ferisman, \& Tualar Simarmata 2011).
Produk organik yang dikonsumsi secara berkala, menurut testimoni pelanggan, dapat menghasilkan efek kesembuhan dari penyakit PTM kanker setelah 5 tahun dibantu dengan konsumsi sayur mentah organik, kondisi badan menjadi lebih sehat dan segar setelah satu tahun mengkonsumsi produk organik (beras, sayur-mayur, buah-buahan, dan produk hewani), dan mendapat pengalaman hidup yang lebih tenang sejak pertama kali mengkonsumsi produk organik (Lichtfouse 2012; Brevik \& Sauer 2015; Corkery 2015; Dhandevi \& Jeewon 2015; Simanjuntak 2015).

Olah tanah berbasis keanekaragaman hayati membutuhkan waktu yang relatif lama (Rouf Alghifari, Dinul Dzakiah, \& Khulwatul Jannah Asrin 2019) karena sangat dipengaruhi oleh faktor iklim yang perubahannya tidak dapat dikendalikan oleh manusia. Jika praktek olah tanah berbasis keanekaragaman hayati dilakukan untuk pencapaian ketahanan pangan maka pengetahuan dan keterampilan praktek budi daya konservasi dilakukan secara lebih luas dan terpadu oleh lembaga terkait antara lain Pemberdayaan Kesejahteraan Keluarga (PKK) yang anggotanya didominasi oleh ibu rumah tangga (Simanjuntak et al. 2019) dan Karang Taruna untuk menggerakkan partisipasi orang muda agar mempunyai pengetahuan dan persepsi yang lebih baik mengenai keragaman bahan makanan (Simanjuntak 2017) menuju hidup yang lebih sehat dan sejahtera.

\section{PENUTUP}

Olah tanah untuk produksi sayuran yang berbasis pada keanekaragaman hayati melalui pertanian organis mengutamakan fungsi tanah sebagai fasilitas lingkungan hidup dan interaksi antar komponen ekosistem yang mendukung kualitas tanah. Fungsi tanah secara maksimum dapat mendukung ketahanan pangan ketika praktek budi daya yang dilakukan bersifat konservasi karena ketahanan pangan memiliki sifat berkelanjutan (sustainable).

Kehidupan sehat dan sejahtera melalui olah tanah berbasis keanekaragaman hayati hanya dapat tercapai ketika kondisi lingkungan hidupnya berkelanjutan. Bagi rumah tangga yang terbatas atau tidak memiliki luasan tanah, olah tanah berbasis keanekaragaman hayati dapat dilakukan dengan budi daya vertikal yang memanfaatkan wadah (sampah) plastik sebagai media tanam dan daur ulang sampah 
dapur yang telah dipilah dari sampah plastik dan non organik lainnya sebagai hara tanah.

Aspek pemasaran dan sertifikasi produk organik tidak dibahas dalam artikel ini karena kajian terkait ketersediaan produk organik yang berkelanjutan untuk memenuhi permintaan konsumen bersifat multi disiplin dan dimensi sehingga artikel terpisah akan memberi kajian yang lebih komprehensif dan mendalam. Di sisi lain, kepercayaan konsumen terhadap produk organik juga perlu mendapat perlakuan yang layak terkait keadilan ekologis yang jika tidak diutamakan akan menghilangkan prinsip konservasi dalam praktek budi daya.

\section{UCAPAN TERIMA KASIH}

Terima kasih kepada Pertanian Organis BSB Cisarua, Bogor yang telah menyedikan kesempatan seluas-luasnya untuk kepentingan pengambilan data penelitian di tahun 2006, dan Universitas Kristen Indonesia, khususnya Prodi Pendidikan Kimia Fakultas Keguruan dan Ilmu Pendidikan yang selalu memberi perhatian dan dukungan kepada penulis baik sebagai dosen pengampu mata kuliah maupun sebagai peneliti isu-isu terkait yang relevan dengan penulisan artikel ilmiah ini.

\section{DAFTAR PUSTAKA}

Barrett, Christopher B., and Leah EM Bevis. 2015. "The self-reinforcing feedback between low soil fertility and chronic poverty." Nature Geoscience 8, no. 12: 907-912.

Brevik, E. C., and T. J. Sauer. 2015. "The past, present, and future of soils and human health studies." Soil 1, no. 1: 35. doi:10.5194/soil-1-35-2015.

Corkery, Linda. 2015. "BEYOND THE PARK: Linking urban greenspaces, human wellbeing and environmental health." In The Routledge Handbook of Planning for Health and Well-Being, pp. 273-287. London: Routledge.

Dhandevi, P. E. M., and Rajesh Jeewon. 2015. "Fruit and vegetable intake: benefits and progress of nutrition education interventions-narrative review article." Iranian journal of public health 44, no. 10: 1309.
Ermalena, M. H. S., and WKKID RI. 2017. "Indikator Kesehatan SDGs di Indonesia." The 4th ICTOH, Jakarta.

Frąc, Magdalena, Silja E. Hannula, Marta Bełka, and Małgorzata Jędryczka. 2018. "Fungal biodiversity and their role in soil health." Frontiers in microbiology 9: 707.

Gregorich, Edward Gerard, and Martin R. Carter, eds. 1997. Soil quality for crop production and ecosystem health. Elsevier.

Groffman, Peter M., Timothy J. Fahey, Melany C. Fisk, Joseph B. Yavitt, Ruth E. Sherman, Patrick J. Bohlen, and John C. Maerz. 2015. "Earthworms increase soil microbial biomass carrying capacity and nitrogen retention in northern hardwood forests." Soil Biology and Biochemistry 87: 51-58.

Kementerian Lingkungan Hidup dan Kehutanan. 31 Desember 2018. "KLHK Tingkatkan Rehabilitasi Hutan dan Lahan Sepuluh Kali Lipat di 2019." Diakses pada tanggal 16 April 2020 pukul 20.00 WIB dari https://ppid.menlhk.go.id/siaran_pers/bro wse/1723.

Lal, Rattan, and Bobby Alton Stewart. 2010. Food security and soil quality. Boca Raton: CRC Press.

Lehman, R. Michael, Veronica AcostaMartinez, Jeffrey S. Buyer, Cynthia A. Cambardella, Harold P. Collins, Thomas F. Ducey, Jonathan J. Halvorson et al. 2015. "Soil biology for resilient, healthy soil." Journal of Soil and Water Conservation 70, no. 1: 12A-18A.

Lichtfouse, Eric, ed. $2010 . \quad$ Genetic engineering, biofertilisation, soil quality and organic farming. Vol. 4. Springer Science \& Business Media.

Lichtfouse, Eric, ed. 2012. Organic fertilisation, soil quality and human health. Vol. 9. Springer Science \& Business Media.

Marsden, Terry, and Roberta Sonnino. 2012. "Human health and wellbeing and the sustainability of urban-regional food systems." Current Opinion in Environmental Sustainability 4, no. 4: 427-430.

Napirah, Muh Ryman, Abd Rahman, and Agustina Tony. 2016. "Faktor-Faktor Yang Berhubungan Dengan 
Pemanfaatan Pelayanan Kesehatan Di Wilayah Kerja Puskesmas Tambarana Kecamatan Poso Pesisir Utara Kabupaten Poso." Jurnal Pengembangan Kota 4, no. 1: 29-39.

Rahmi, Zardina Putri. 2017. "Kerugian Ekonomi pada Rumah Tangga Akibat Hipertensi di Wilayah Kerja Puskesmas Ulak Karang Tahun 2016." PhD diss., Universitas Andalas.

Rouf AlGhifari, Ahmad, Lelis Dinul Dzakiah, and Lulu Khulwatul Jannah Asrin. 2019. "Erosi sebagai penyebab utama degradasi lahan." Agroteknologi: 1-11.

Schjønning, Per, Susanne Elmholt, and Bent Tolstrup Christensen, eds. 2003. Managing soil quality: challenges in modern agriculture. Denmark: CABI.

Simanjuntak, Familia Novita. 2006. "Penerapan pertanian organik untuk mengendalikan kualitas kesuburan tanah dan menghasilkan produk pangan bebas pestisida (studi kasus pertanian organik bina sarana bhakti Cisarua, Bogor)." Thesis, Pasca Sarjana-UI.

Simanjuntak, Familia Novita. 2015. "Pendidikan kimia bahan makanan untuk membangun kesadaran makan makanan sehat." Jurnal Dinamika Pendidikan 8, no. 1: 11-18.

Simanjuntak, Familia Novita. 2017. "Teenagers' Knowledge and Perception about The Staple Food Diversity to Describe Daily Eating Habit." $8^{\text {th }}$ International Conference of Asian Association of Indigenous and Cultural Psychology (ICAAIP 2017). https://dx.doi.org/10.2991/icaaip17.2018.1

Simanjuntak, Familia Novita, Leony Sanga Lamsari Purba, Nova Irawati Simatupang, and St Fatimah Azzahra. 2019. "Peningkatan PengetahuanKimia dalam Kehidupan Sehari-hari pada Ibu Rumah Tangga Perkotaan Kelas Ekonomi Menengah." JURNAL ComunitÃ Servizio: Jurnal Terkait Kegiatan Pengabdian kepada Masyarakat, terkhusus bidang Teknologi, Kewirausahaan dan Sosial Kemasyarakatan 1, no. 2: 98-108.

Syarifain, Abdul, Adisti A. Rumayar, and Chreisye KF Mandagi. 2017. "Hubungan antara Pendidikan dan Pendapatan dengan Pemanfaatan Pelayanan
Kesehatan oleh Pasien BPJS di Wilayah Kerja Puskesmas Sario Kota Manado." KESMAS 6, no. 4.

Taylor, Lucy, and Dieter F. Hochuli. 2015. "Creating better cities: how biodiversity and ecosystem functioning enhance urban residents' wellbeing." Urban ecosystems 18, no. 3: 747-762. doi:10.1007/s11252-014-0427-3.

Tindaon, Ferisman, and Tualar Simarmata. 2011. "Percepatan Pemulihan Kesehatan Lahan Untuk Meningkatkan Produktivitas Tanah Dan Membangun Kemandirian Pangan di Indonesia." VISI 19 (2):523-532 